\title{
PYED-1 Inhibits Biofilm Formation and Disrupts the Preformed Biofilm of Staphylococcus aureus
}

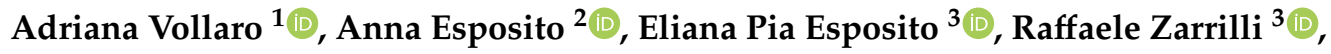 \\ Annalisa Guaragna ${ }^{2, *(D)}$ and Eliana De Gregorio ${ }^{1, *(D)}$ \\ 1 Department of Molecular Medicine and Medical Biotechnology, University of Naples Federico II, \\ 80131 Naples, Italy; vollaroadriana@libero.it \\ 2 Department of Chemical Sciences, University of Naples Federico II, 80126 Naples, Italy; \\ anna.esposito5@unina.it \\ 3 Department of Public Health, University of Naples Federico II, 80131 Naples, Italy; \\ elianapia.esposito@unina.it (E.P.E.); rafzarri@unina.it (R.Z.) \\ * Correspondence: annalisa.guaragna@unina.it (A.G.); edegrego@unina.it (E.D.G.)
}

Received: 19 April 2020; Accepted: 6 May 2020; Published: 8 May 2020

check for updates

\begin{abstract}
Pregnadiene-11-hydroxy-16 $\alpha, 17 \alpha$-epoxy-3,20-dione-1 (PYED-1), a heterocyclic corticosteroid derivative of deflazacort, exhibits broad-spectrum antibacterial activity against Gram-negative and Gram-positive bacteria. Here, we investigated the effect of PYED-1 on the biofilms of Staphylococcus aureus, an etiological agent of biofilm-based chronic infections such as osteomyelitis, indwelling medical device infections, periodontitis, chronic wound infections, and endocarditis. PYED-1 caused a strong reduction in biofilm formation in a concentration dependent manner. Furthermore, it was also able to completely remove the preformed biofilm. Transcriptional analysis performed on the established biofilm revealed that PYED-1 downregulates the expression of genes related to quorum sensing (agrA, RNAIII, hld, psm, and sarA), surface proteins (clfB and fnbB), secreted toxins (hla, hlb, and $l u k D)$, and capsular polysaccharides $(\operatorname{cap} C)$. The expression of genes that encode two main global regulators, $s i g B$ and $s a e R$, was also significantly inhibited after treatment with PYED-1. In conclusion, PYED-1 not only effectively inhibited biofilm formation, but also eradicated preformed biofilms of $S$. aureus, modulating the expression of genes related to quorum sensing, surface and secreted proteins, and capsular polysaccharides. These results indicated that PYED-1 may have great potential as an effective antibiofilm agent to prevent $S$. aureus biofilm-associated infections.
\end{abstract}

Keywords: biofilm formation; preformed biofilm; antibiofilm activity; biofilm eradication agent; Staphylococcus aureus; corticosteroid

\section{Introduction}

One of the bacterial growth modes is the development of biofilms, which may be considered a basic survival strategy in hostile environments [1]. Biofilms are sessile communities of bacterial cells, attached to each other and/or to surfaces, embedded in a self-produced matrix of extracellular polymeric substances (EPS) [2]. Biofilm formation plays a crucial role in bacterial infection and antimicrobial resistance, because biofilm-embedded bacteria are more resistant to common antimicrobial agents and host defense systems than bacteria in the planktonic state [3]. Increasing evidence demonstrates that cells in biofilms on a biotic or abiotic surface are 1000-fold more resistant to conventional drugs than planktonic cells $[4,5]$. Once established, biofilms become difficult to eradicate, leading to chronic and persistent infections [6]. Staphylococcus aureus is the major Gram-positive pathogen which causes biofilm-associated infections, because of its ability to form biofilms on a wide range of surfaces $[7,8]$. 
As a result of this, there is an urgent need to develop new agents that inhibit S. aureus biofilm formation, and/or disrupt established biofilms [9]. In previous studies, we showed that pregnadiene-11-hydroxy-16 $\alpha, 17 \alpha$-epoxy-3,20-dione-1 (PYED-1) exhibits effective antibacterial activity against S. aureus ATCC 29213 and A. baumannii ATCC 17978, without cytotoxic effects [10,11]. Additionally, we demonstrated that PYED-1 at sub-inhibitory concentrations hinders the biofilm formation of the Stenotrophomonas maltophilia K279a strain [12].

In this study, we investigated the in vitro effect of PYED-1 on biofilm formation and eradication of preformed biofilm by $S$. aureus.

\section{Results and Discussion}

\subsection{Effect of PYED-1 on S. aureus Biofilm Formation}

S. aureus has the ability to produce a biofilm, which protects it from the action of antibacterial drugs [13]. The development of antibiofilm agents may be a potential approach for the management of disease progression, and elimination of this pathogen from the target site of infection [14]. Previous studies have shown that higher doses of topical corticosteroids (budesonide, mometasone, and fluticasone), commonly used in the treatment of chronic rhinosinusitis, have effective antibiofilm activity against $S$. aureus [15]. Recent studies have shown that PYED-1 at $16 \mu \mathrm{g} / \mathrm{mL}$ exerts effective inhibitory activity of planktonic cell growth against S. aureus ATCC 29213 [10,11].

S. aureus cells were treated with PYED-1 at sub-minimal inhibitory concentrations (MICs) (0.25 to $8 \mu \mathrm{g} / \mathrm{mL}$ ), and the biofilm biomass was quantified by crystal violet (CV) staining assay. PYED-1 caused a two-fold inhibition of biofilm formation at $0.25 \mu \mathrm{g} / \mathrm{mL}(1 / 64 \times \mathrm{MIC})$. When PYED-1 was added at $8 \mu \mathrm{g} / \mathrm{mL}(1 / 2 \times \mathrm{MIC})$, complete inhibition of biofilm formation was observed (Figure $1 \mathrm{~A})$.

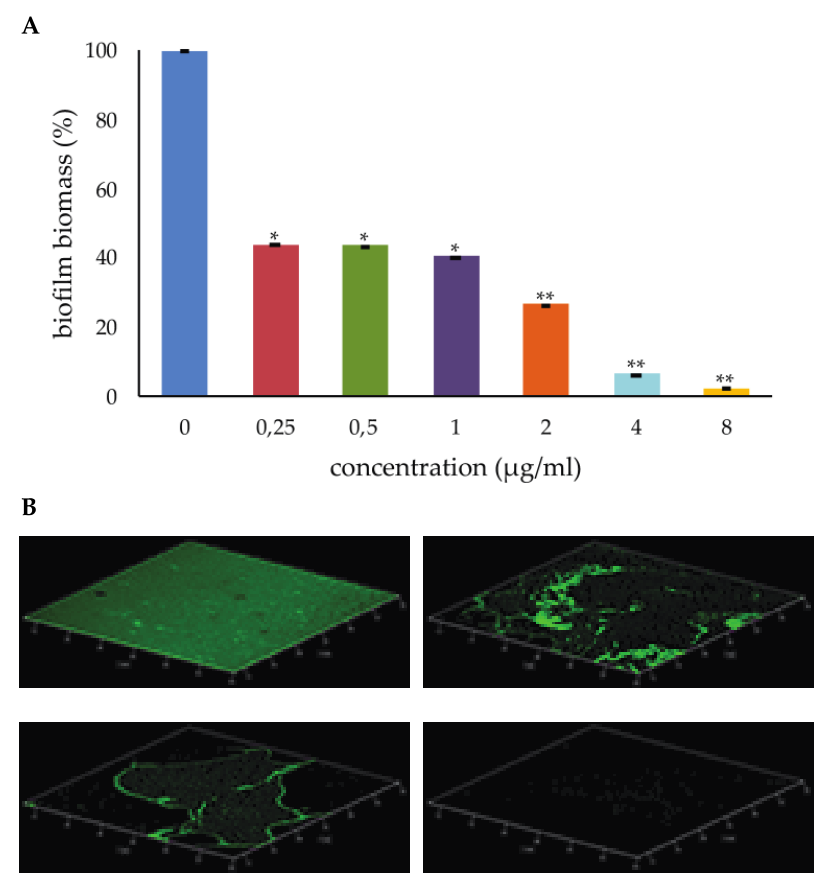

Figure 1. Inhibitory effect of pregnadiene-11-hydroxy-16 $\alpha, 17 \alpha$-epoxy-3,20-dione-1 (PYED-1) on S. aureus biofilm formation. (A) Biofilms were quantified after crystal-violet staining. Values are presented as means \pm SDs. Asterisks indicate statistically significant differences between the treated and untreated biofilms ${ }^{*} p<0.05$ and ${ }^{* *} p<0.01$, respectively). (B) Confocal laser scanning microscopy (CLSM) analysis of the biofilm formed by S. aureus ATCC 29213 in the absence (left upper panel) or presence of PYED-1, at the concentrations of $2 \mu \mathrm{g} / \mathrm{mL}$ (right upper panel), $4 \mu \mathrm{g} / \mathrm{mL}$ (left inferior panel), and $8 \mu \mathrm{g} / \mathrm{mL}$ (right inferior panel). 
Furthermore, PYED-1 at concentrations of up to $8 \mu \mathrm{g} / \mathrm{mL}$ did not impair planktonic growth at concentrations of up to $8 \mu \mathrm{g} / \mathrm{mL}$ (data not shown), thus suggesting that the reduction of biofilm formation caused by PYED-1 was due to its antibiofilm activity, and not to its antimicrobial activity. Similar results were obtained in previous studies on $S$. maltophilia [12], in which treatment with PYED-1 at $1 / 4 \times \mathrm{MIC}, 1 / 8 \times \mathrm{MIC}$, and 1/16× MIC was able to inhibit biofilm formation by $97 \%, 90 \%$, and $57 \%$, respectively, compared with the untreated control. Biofilm formation was also assessed qualitatively using confocal laser scanning microscopy (CLSM). S. aureus cells were incubated with or without 2, 4 , and $8 \mu \mathrm{g} / \mathrm{mL}$ of PYED-1 for $24 \mathrm{~h}$ and stained using SYTO 9 and propidium iodide fluorophores to visualize live and dead cells, respectively (Figure 1B). The CLSM results confirmed the inhibition of biofilm formation in a concentration-dependent manner. This analysis revealed a thick biofilm coverage in the control sample, while PYED-1 treated samples showed a visible reduction in the coverage of biofilm. A clear reduction of the number of bacteria was observed even at the concentration of $2 \mu \mathrm{g} / \mathrm{mL}$ PYED-1 (Figure 1B, right upper panel). Treatment of the biofilm with $8 \mu \mathrm{g} / \mathrm{mL}$ PYED-1 for $24 \mathrm{~h}$ resulted in the complete absence of adherent cells (Figure 1B, right inferior panel).

The ability of PYED-1 to completely inhibit S. aureus biofilm formation makes it a promising drug to control S. aureus biofilm growth.

\subsection{Effect of PYED-1 against S. aureus Preformed Biofilm}

Mature biofilms are more difficult to treat than those at early stages, because they represent a physical barrier to drug crossing and exhibit increased drug resistance [14]. In this regard, infections in which the formation of biofilms represents a severe complication might be eradicated by using antibiofilm agents that weaken or destroy preformed biofilm cells [16], ultimately leading to biofilm disappearance [17]. As a result, that complete inhibition of biofilm formation was obtained following treatment with PYED-1 concentrations corresponding to 1/2× MIC (Figure 1), PYED-1 concentrations higher than those inhibiting biofilm growth were analyzed for their effects on preformed biofilms. To investigate this issue, one day old biofilms were exposed to PYED-1 at the concentration of $1 \times$ MIC $(16 \mu \mathrm{g} / \mathrm{mL}), 2 \times \mathrm{MIC}(32 \mu \mathrm{g} / \mathrm{mL})$, and $4 \times \mathrm{MIC}(64 \mu \mathrm{g} / \mathrm{mL})$ for $24 \mathrm{~h}$. Biofilm biomass and biofilm viability were measured by $\mathrm{CV}$ staining and tetrazolium salt reduction (XTT) assay, respectively. PYED-1 treatment at $1 \times$ MIC, 2× MIC, and 4× MIC values decreased biofilm biomass by $80 \%, 90 \%$, and $94 \%$ compared to the untreated biofilm, respectively (Figure $2 \mathrm{~A}$ ). The biofilm metabolic activity, as assessed through XTT assay, showed that PYED-1 reduced the viability of $S$. aureus biofilm cells by $70 \%, 80 \%$ and $95 \%$ at the concentration of $16 \mu \mathrm{g} / \mathrm{mL}, 32 \mu \mathrm{g} / \mathrm{mL}$, and $64 \mu \mathrm{g} / \mathrm{mL}$, respectively (Figure 2B).

Visualization of the biofilms by CLSM confirmed these results. One-day-old S. aureus biofilms were treated with 16, 32, or $64 \mu \mathrm{g} / \mathrm{mL}$ PYED-1 for $24 \mathrm{~h}$, stained with the Baclight Live/Dead reagent, and observed using CLSM (Figure 2C).The CLSM results showed that increasing PYED-1 concentrations reduced the number of adherent bacteria to the slide, and consequently the biofilm biomass. Biofilm formation reduces penetration of most antibiotics, and thus their effectiveness [18]. Moreover, a slow penetration of antibiotics into bacterial cells can induce an adaptive phenotypic response that might potentially increase tolerance [19]. Furthermore, bacteria in biofilms are poorly eliminated by the immune system [18,20].

Consequently, the finding that PYED-1 is able to destroy existing biofilms and inhibit the continued formation of biofilms has relevance, making this substance attractive for potential use in therapeutic regimens. 

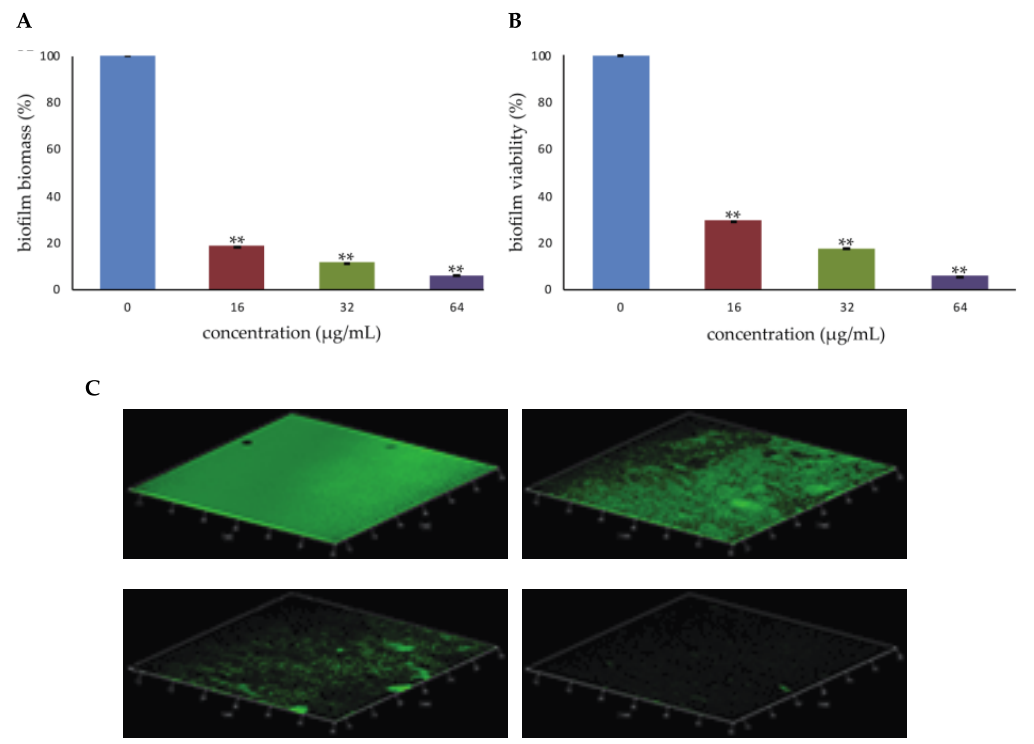

Figure 2. Eradicating effect of PYED-1 on S. aureus preformed biofilm. Biofilm formed after $48 \mathrm{~h}$ in 96-well microplates was treated with different PYED-1 concentrations for $24 \mathrm{~h}$ at $37^{\circ} \mathrm{C}$ under static conditions. (A) Biofilm biomass were measured by crystal violet (CV) staining. (B) Biofilm viability was measured by tetrazolium salt reduction (XTT) assay. Error bars represent the standard deviation (SD) of three independent experiments. Asterisks indicate statistically significant differences between the treated and untreated biofilms (** $p<0.01)$. (C) CLSM analysis of preformed S. aureus ATCC 29213 biofilm without treatment (left upper panel) or treated with PYED-1 at $16 \mu \mathrm{g} / \mathrm{mL}$ (right upper panel), $32 \mu \mathrm{g} / \mathrm{mL}$ (left inferior panel), and $64 \mu \mathrm{g} / \mathrm{mL}$ (right inferior panel) for $24 \mathrm{~h}$.

\subsection{Biofilm Gene Expression}

Our previous data showed that PYED-1 inhibition of S. aureus biofilm formation is associated with reduced expression of several genes involved in S. aureus virulence [11]. Here, we investigated the molecular mechanism responsible for the eradication activity of PYED-1. In an attempt to understand how PYED-1 removes established biofilms, we measured the transcriptional responses of S. aureus preformed biofilm cells exposed to a $1 \times$ MIC value of PYED-1. RNA was purified from the samples and analyzed by quantitative RT-PCR (qRT-PCR) to assess the effect of PYED-1 exposure on the gene expression of the biofilm cells (Figure 3).

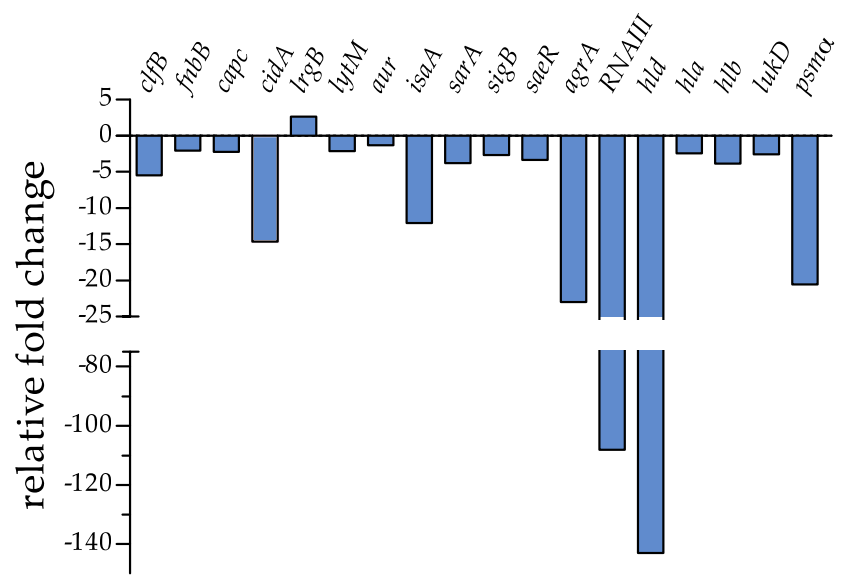

Figure 3. Transcriptional profile changes in S. aureus after treatment with PYED-1, determined by qRT-PCR with respect to $r p o B$ expression. Fold-changes were calculated using treated versus untreated S. aureus cells. Gene descriptions, fold changes, standard deviations (SD), and $p$-values are reported in Table 1. 
Table 1. RT-PCR analysis of biofilm gene expression in S. aureus ATCC 29213 in the presence of PYED-1.

\begin{tabular}{lllc}
\hline Gene & Description & Fold Change \pm SD & $p$-Value \\
\hline clfB & clumping factor B & $-5.44 \pm 0.011$ & 0.0004 \\
fnbB & fibronectin-binding protein B & $-2.03 \pm 0.029$ & 0.0025 \\
capC & capsule biosynthesis protein C & $-2.22 \pm 0.027$ & 0.0019 \\
cidA & holin-like murein hydrolase modulator & $-14.67 \pm 0.004$ & $<0.0001$ \\
lrgB & antiholin-like protein B & $+2.65 \pm 0.160$ & 0.0013 \\
lytM & peptidoglycan hydrolase & $-2.09 \pm 0.028$ & 0.0022 \\
aur & aureolysin, zinc metalloproteinase & $-1.32 \pm 0.045$ & 0.0155 \\
isaA & immunodominant staphylococcal antigen & $-12.06 \pm 0.005$ & $<0.0001$ \\
sarA & Transcriptional regulator & $-3.77 \pm 0.016$ & 0.0007 \\
sigB & RNA polymerase sigma factor B & $-2.67 \pm 0.022$ & 0.0013 \\
saeR & response regulator SaeR & $-3.34 \pm 0.018$ & 0.0008 \\
agrA & accessory gene regulator protein A & $-22.99 \pm 0.002$ & 0.0001 \\
RNAIII & small regulatory RNA & $-108.14 \pm 0.0005$ & $<0.0001$ \\
hld & delta-haemolysin gene & $-143.04 \pm 0.0004$ & $<0.0001$ \\
hla & alpha-haemolysin & $-2.41 \pm 0.025$ & 0.0016 \\
hlb & beta-haemolysin & $-3.83 \pm 0.015$ & 0.0007 \\
lukD & pore-forming leukocidin & $-2.56 \pm 0.023$ & 0.0014 \\
psma & Phenol-soluble modulin & $-20.54 \pm 0.002$ & 0.0001 \\
sarA & Transcriptional regulator & $-3.77 \pm 0.016$ & 0.0007 \\
\hline
\end{tabular}

The extracellular matrix of $S$. aureus biofilm, composed of polysaccharide intracellular adhesin (PIA), teichoic acids, extracellular DNA (eDNA), and several surface proteins, is crucial for the structural integrity of biofilms [21]. Analyses of differentially expressed genes revealed that most of the analyzed genes involved in the maintenance of mature biofilms were downregulated, except the $\operatorname{lrg} B$ gene (Table 1 and Figure 3). Positively charged cytoplasmic proteins, among which fibronectin-binding proteins $\mathrm{A}$ and $\mathrm{B}$ (FnbA and FnbB) and clumping factors $\mathrm{A}$ and $\mathrm{B}$ (ClfA and ClfB), interact with eDNA released during cell autolysis and negatively charged phospholipids and teichoic acids [22]. The addition of PYED- 1 to preformed S. aureus biofilms affected expression of both the $f n b B$ and $c l f B$ genes (Table 1 and Figure 3).

DNA released by cell autolysis is an essential component of the S. aureus biofilm matrix [23]. The release of DNA is regulated by the cid and $\operatorname{lrg}$ genes [24,25]. The cidA gene encodes a murein hydrolase regulator that promotes cell lysis, while lrg genes encode proteins that inhibit cell lysis by preventing homo-oligomerization of cid gene products [26]. The transcript levels of the positive regulator cidA were notably decreased (about a 15-fold reduction), and the transcript levels of the negative regulator of autolysis $\operatorname{lrg} B$ were increased 2.65-fold (Table 1 and Figure 3). These results suggest that PYED-1 could reduce $S$. aureus preformed biofilms by inhibiting autolysis. Our results are in agreement with previous studies showing that licochalcone A, tea tree oil, and magnolol reduce $S$. aureus biofilm production by reducing the expression of $\operatorname{cidA}$ and increasing the expression of $\operatorname{lrg} B[27-29]$.

We also examined the expression of autolysin-encoding genes. PYED-1 significantly reduced the expression of the lytM gene, which encodes a glycyl-glysine endopeptidase (Table 1 and Figure 3 ). This is in agreement with previous studies showing that the exposure of $S$. aureus biofilm to the lytic proteins LysH5 and CHAPSH3b downregulates several autolysin-encoding genes [30]. The transcriptional levels of isaA (immunodominant staphylococcal antigen) were also markedly (12-fold) reduced (Table 1 and Figure 3). In contrast, the transcriptional levels of is $A$ were increased by PYED-1 in planktonic cells [11]. Changes in the transcriptional control of isaA in planktonic cells and preformed biofilms were also observed when treating planktonic and biofilm cells with secalonic acid D [31].

Several global regulators, such as the accessory gene regulator (agr) system, sigma factor B (SigB), staphylococcal accessory regulator (SarA), and two component system SaeRS, modulate biofilm formation in S. aureus [32]. The expression of the saeR and sarA genes was downregulated 3.34- and 
3.77-fold by PYED-1 treatment, respectively (Table 1 and Figure 3). The SaeR regulator controls the expression of genes encoding major virulence factors, such as hla and $h l b$ ( $\alpha$-and $\beta$-hemolysin), coa (coagulase), eap (extracellular adherence protein), and fnbA/B genes [33], some of which contribute to the ability of $S$. aureus to survive in neutrophils [34]. Indeed, the downregulation of the sae operon may reduce the escape of $S$. aureus from PMNs [35]. The SarA regulator enhances the transcription of matrix adhesion genes, including $f n b A$ and $f n b B$ [36]. The mutation of the $s a r A$ gene reduces accumulation of $\alpha$-toxin and phenol soluble modulins (PSMs) [37]. Not surprisingly, the levels of some genes regulated by the two regulators, such $f n b B, h l a, h l b$, and $p s m$, were also notably reduced (Table 1 and Figure 3). PSMs [21] and beta-hemolysin [38] have been shown to bind eDNA, promoting the formation of amyloid-like fibers that stabilize the extracellular matrix and consequently $S$. aureus biofilms. A minor accumulation of PSMs was observed in a sarA mutant [39], therefore the observed reduction of $p s m$ gene expression could also be correlated with the downregulation of the sarA gene. Moreover, SaeR and SarA also synergistically repress the production of proteases [39], which are involved in biofilm detachment. We speculated that the downregulation of saeRS and sarA by PYED-1 treatment may also promote the production of extracellular nucleases and proteases, limiting the accumulation of the eDNA and proteins that promote biofilm formation, thus favoring biofilm detachment. In further support of this hypothesis, compounds targeting the expression of sarA have been shown to have potent antibiofilm and anti-virulence activity [40,41].

In the conditions under which we aimed to remove biofilms, the agr $A$ gene and the small non-coding RNAIII, associated with the quorum sensing systems of $S$. aureus, were markedly downregulated by 22.99- and 108.14-fold, respectively, following treatment with a $1 \times$ MIC value of PYED-1 (Table 1 and Figure 3). The transcript levels of hld, which encodes delta-hemolysin, were downregulated by a factor of 143.04. The agr expression was activated by SarA, therefore the observed reduction of agr expression could be also correlated with the downregulation of the sarA gene. In turn, RNAIII regulates the expression of secreted virulence factors, including the alfa-, beta-, and delta-hemolysins [42].

The alternative sigma factor, $\mathrm{SigB}$, that leads global changes in gene expression, is known to control sar $A$ expression [43]. After treatment of the preformed biofilms with PEYD-1 the expression of the sig $B$ gene was downregulated 2.67-fold (Table 1 and Figure 3). A lower sig $B$ expression could partly account for the sar $A$ downregulation observed in our experiments. It has been shown that sigB-deficient $S$. aureus are unable to form biofilms and feature increased RNA III production [44], leading to up-regulation of proteases. PYED-1 decreased the RNA III level, suggesting that up-regulation of the RNAIII level via a decreased SigB level could be compensated for by changes in other genes that may also regulate the RNAIII level.

Exposure to a $1 \times$ MIC value of PYED-1 moderately reduced the expression of the $\operatorname{cap} C$ gene (Table 1 and Figure 3). Reduced capsule production may render an organism more sensitive to phagocytosis [45].

Based on the above findings, we conclude that the eradication of S. aureus preformed biofilms is associated with downregulation of the expression of several biofilm- and toxin-related genes.

\section{Materials and Methods}

\subsection{Effect of PYED-1 on S. aureus Biofilm Formation}

The chemical synthesis and structural characterization of PYED-1 was realized as previously reported [10,11]. PYED-1 was dissolved in dimethyl sulfoxide (DMSO) to the concentration of $50 \mathrm{mg} / \mathrm{mL}$. Two-fold serial dilutions of the compounds were prepared in ultrapure DNase/RNase-free distilled water (Thermo Fisher Scientific, catalog number 10977035). The biofilm prevention efficacy of PYED-1 was assayed using the crystal violet (CV) biofilm staining method [46]. A bacterial cell suspension $\left(5 \times 10^{6}\right.$ cells $/ \mathrm{mL}$ in TSB supplemented with $0.5 \%$ glucose $)$ was aliquoted $(100 \mu \mathrm{L} /$ well $)$ in a 96 -well flat bottomed polystyrene microtiter plate, treated or not with $100 \mu \mathrm{L}$ of scalar doses of PYED-1 (the concentrations ranged from $0.25 \mu \mathrm{g} / \mathrm{mL}$ to $8 \mu \mathrm{g} / \mathrm{mL}$ ). Non-treated bacteria were incubated with $100 \mu \mathrm{L}$ 
of broth containing scalar doses of DMSO (range concentrations from $0.0005 \%$ to $0.016 \%$ ) and used as the control. After $24 \mathrm{~h}$ of incubation at $37^{\circ} \mathrm{C}$, the supernatant was gently removed, and the wells were washed twice with $200 \mu$ l of phosphate-buffered saline (PBS) 1X pH 7.4 (Thermo Fisher Scientific, catalog number 10010015). The plates were dried at $60{ }^{\circ} \mathrm{C}$ for $30 \mathrm{~min}$, and the biofilms were stained with $200 \mu \mathrm{L}$ of $0.1 \%$ crystal violet for 15 minutes. After washing with $200 \mu \mathrm{L}$ of PBS $1 \times$, the wells were filled with $200 \mu \mathrm{L}$ of $96 \%$ ethanol, incubated for 20 minutes at room temperature, and the absorbance was measured at $595 \mathrm{~nm}$ using a microplate reader (Bio-Rad Laboratories S.r.l.). The percentage of biofilm mass reduction was calculated as follows: [(Ac-At)/Ac] $\times 100$, where Ac is the OD595 for the control well and At is the OD595 for the biofilm in the presence of PYED-1. All data points are expressed as means \pm SDs of three separate experiments performed in triplicate.

\subsection{Effect of PYED-1 against Preformed Biofilm Biomasses}

Biofilms were allowed to form in each well of a 96-well microtiter plate, as described above. After $24 \mathrm{~h}$ the planktonic cells were gently removed by aspiration, and the plate was washed with $200 \mu \mathrm{L}$ of PBS $1 \times$. Two hundred microliters of PYED-1 was added at concentrations ranging from $16 \mu \mathrm{g} / \mathrm{mL}$ to $64 \mu \mathrm{g} / \mathrm{mL}$, and the plate was incubated for $24 \mathrm{~h}$ at $37^{\circ} \mathrm{C}$. Non-treated cells were incubated with $200 \mu \mathrm{L}$ of broth containing scalar doses of DMSO (concentrations ranging from $0.032 \%$ to $0.128 \%$ ). Following the incubation, crystal violet-staining was performed to assess the biofilm biomass. All data points are expressed as means \pm SDs of three separate experiments performed in triplicate.

\subsection{Effect of PYED-1 against Preformed Biofilm Viability}

Biofilms were allowed to form in each well and were treated following $24 \mathrm{~h}$ of incubation, as described above. After PYED-1 treatment, $150 \mu$ l of a mixed solution of XTT [2,3-bis(2-methyloxy-4nitro-5-sulfophenyl)-2H-tetrazolium-5-carboxanilide] and N-methyl dibenzopyrazine methyl sulfate (Roche Diagnostics) was added to each well. Following incubation in the dark for $40 \mathrm{~min}$ at $37^{\circ} \mathrm{C}$, the biofilm metabolic activity was determined through the measurement of the absorbance value at $490 \mathrm{~nm}$, using a microplate reader (Bio-Rad Laboratories S.r.1.). Viability values were compared with respect to control samples treated with scalar doses of DMSO (concentrations ranging from 0.032\% to $0.128 \%$ ). All data points are expressed as means \pm SDs of three separate experiments performed in triplicate.

\subsection{Confocal Laser Scanning Microscopy (CLSM)}

For CLSM analysis of biofilm formation, S. aureus cells were allowed to form biofilms in chambered cover glasses ( $\mu$ Slide 4 well; Ibidi GmbH, Munich, Germany) in the presence of PYED-1 (concentrations ranged from $2 \mu \mathrm{g} / \mathrm{mL}$ to $8 \mu \mathrm{g} / \mathrm{mL}$ ) or of scalar doses of DMSO (concentrations ranging from $0.032 \%$ to $0.128 \%$ ) for $24 \mathrm{~h}$ at $37^{\circ} \mathrm{C}$ in static conditions. For CLSM analysis of preformed biofilms, the biofilms were allowed to form in each chambered cover glass and then were treated with PYED-1 (concentrations ranging from $16 \mu \mathrm{g} / \mathrm{mL}$ to $64 \mu \mathrm{g} / \mathrm{mL}$ ) or scalar doses of DMSO (concentrations ranging from $0.032 \%$ to $0.128 \%$ ) for $24 \mathrm{~h}$ at $37^{\circ} \mathrm{C}$ in static conditions. Then, the biofilms were washed with sterile PBS $1 \times$ and stained with LIVE/DEAD BacLight Bacteria Viability stains (Life Technologies, Monza, Italy), a mixture of green-fluorescent nucleic acid stain SYTO 9 and the red-fluorescent nucleic acid stain propidium iodide (PI). Briefly, $200 \mu \mathrm{L}$ of dye solution was added to the well and incubated at room temperature for $15 \mathrm{~min}$ in the dark. After incubation, the stain was removed, and wells were washed with distilled water. Stained biofilms were observed using an LSM 700 inverted confocal laser-scanning microscope (Zeiss, Arese, Milan, Italy). Three different areas of each well were scanned using a $10 \times$ lens. Signals were recorded in the green channel for SYTO 9 (excitation $488 \mathrm{~nm}$, emission 500-525 nm) and in the red channel for PI (excitation 500-550 nm, emission 610-650 nm). For CLSM analysis of the preformed biofilms, PYED-1 was added to 1-day-old biofilms at $16 \mu \mathrm{g} / \mathrm{mL}, 32 \mu \mathrm{g} / \mathrm{mL}$, and $64 \mu \mathrm{g} / \mathrm{mL}$. Untreated bacterial suspensions were used as the control. After $24 \mathrm{~h}$, the biofilms were rinsed with PBS $1 \times$ and stained with LIVE/DEAD BacLight Bacteria Viability stains, as described above. 


\subsection{Biofilm Gene Expression}

For RNA isolation, S. aureus ATCC 29213 was grown in 24-well polystyrene tissue culture plates containing TSB supplemented with $0.5 \%$ glucose and incubated at $37^{\circ} \mathrm{C}$. After $24 \mathrm{~h}$ of biofilm growth, the suspension cultures were removed from each well. The plates were washed twice with sterile PBS $1 \times$. A total of $600 \mu \mathrm{L}$ of fresh medium with $0.032 \%$ DMSO or PYED-1 (final concentration $16 \mu \mathrm{g} / \mathrm{mL}$ ) was added to the wells, and the plate was incubated at $37^{\circ} \mathrm{C}$ for $16 \mathrm{~h}$ without shaking. The plates were then washed with PBS $1 \times$ (to remove planktonic cells) and the adherent cells were scraped with a pipettor and placed in the RNAprotect Bacteria Reagent (Qiagen, Germany). The sessile cell suspension was then transferred to a microcentrifuge tube and incubated for $5 \mathrm{~min}$ at room temperature to stabilize the mRNA. Next, the cell suspensions were centrifuged at $5000 \times \mathrm{g}$ for $10 \mathrm{~min}$ to pellet the cells, and the supernatant was decanted. Total RNA was purified according to the previously reported method [47], with some modifications. Pellets were resuspended in $200 \mu \mathrm{L}$ of $20 \mathrm{mg} / \mathrm{mL}$ proteinase $\mathrm{K}$ and $200 \mu \mathrm{L}$ TE buffer (30 mM Tris HCl, $1 \mathrm{mM}$ EDTA, pH 8.0) containing $20 \mathrm{mg} / \mathrm{mL}$ lysozyme and $12.5 \mu \mathrm{g} / \mathrm{mL}$ lysostaphin, and incubated at $37^{\circ} \mathrm{C}$ for $1 \mathrm{~h}$. RNA isolation was performed using the RNeasy Mini Kit (Qiagen), according to the manufacturer's recommended protocol. Residual DNA was removed with the DNase Max Kit (Qiagen). RNA was quantified using a Nano-drop instrument (Thermo Fisher). Total RNA was reverse transcribed into cDNA using the QuantiTect Reverse Transcription Kit (Qiagen), according to the manufacturer's protocol. The RT-PCR was carried out in a $20 \mu \mathrm{L}$ volume, as previously described [48], using an SYBR Green master mix (Applied Biosystems). The primer pairs used in the PCR experiments are reported in Table 2.

Table 2. Gene target list and oligonucleotide sequences.

\begin{tabular}{|c|c|c|}
\hline Gene & Forward primer $\left(5^{\prime}-3^{\prime}\right)$ & Reverse primer $\left(5^{\prime}-3^{\prime}\right)$ \\
\hline $\operatorname{agr} \mathrm{A}$ & TGCGAAGACGATCCAAAAC & TTTAGCTTGCTCAAGCACCTC \\
\hline aur & GATGGTCGCACATTCACAAG & CGCCTGACTGGTCCTTATATTC \\
\hline $\operatorname{capC}$ & CATCCAGAGCGGAATAAAGC & CGGAAATACCCGCTAATGAC \\
\hline $\operatorname{cidA}$ & CTTAGCCGGCAGTATTGTTG & GTTTGCACCGTCTTCTACCC \\
\hline clf B & TTATGGTGGTGGAAGTGCTG & TGGACTTGGTTCTGGATCTG \\
\hline$f n b \mathrm{~B}$ & GAACATGGTCAAGCACAAGG & ACGCCATAATTACCGTGACC \\
\hline hla & TCTTGGAACCCGGTATATGG & AGCGAAGTCTGGTGAAAACC \\
\hline$h l b$ & GTGCCAAAGCCGAATCTAAG & ATCAGCGCGTTTATATTGTCC \\
\hline hld & AAGGAAGGAGTGATTTCAATGG & TTTGTTCACTGTGTCGATAATCC \\
\hline is $a \mathrm{~A}$ & TCCGACAAACACTGTTGACC & AATCCCCAAGCACCTAAACC \\
\hline $\operatorname{lrg} \mathrm{B}$ & TATTGCCCGAGGATTAGCAC & CAAAGACAGGCACAACTGCTAC \\
\hline lyt M & ACGGTGTCGACTATGCAATG & ATTGCCGCCACCATAGTTAC \\
\hline$l u k \mathrm{D}$ & GTACTTAAGGCAGCCGGAAAC & CGCCCCAATAAAACTGTGAG \\
\hline $\operatorname{psm} \alpha$ & TCAAAAGCTTAATCGAACAATTCAC & AATGGCCCCСTTCAAATAAG \\
\hline RNAIII & AAGCCATCCСAACTTAATAACC & GCACTGAGTCCAAGGAAACTAAC \\
\hline rpoB & ACAACCACTTGGCGGTAAAG & ATGCTTCAAGTGCCCATACC \\
\hline $\operatorname{sar} \mathrm{A}$ & TTGCTTTGAGTTGTTATCAATGG & CAATACAGCGAATTCTTCAAAGC \\
\hline sae $\mathrm{R}$ & CCAAGGGAACTCGTTTTACG & ACGCATAGGGACTTCGTGAC \\
\hline $\operatorname{sig} \mathrm{B}$ & TGATCGCGAACGAGAAATC & ATTGCCGTTCTCTGAAGTCG \\
\hline
\end{tabular}

The expressions of genes of interest were normalized to the housekeeping gene rpoB. RNA samples not treated with reverse transcriptase were routinely included as no template controls. Changes in transcript levels were determined using the $2^{-\Delta \Delta C T}$ method [49]. RNA expression levels were determined by using three independent cultures, and all analyses were performed in triplicate.

\subsection{Statistical Analysis}

All statistical analyses were performed with GraphPad prism 8 software (GraphPad, San Diego, CA, USA). Arithmetic means and standard deviations were used to statistically analyze continuous variables. 
Statistical differences between PYED-1 treated and untreated biofilms were analyzed by Student's $\mathrm{t}$ test. A $p$-value $<0.05$ and $<0.001$ in comparison with untreated controls was considered significant.

\section{Conclusions}

The results shown herein demonstrate that PYED-1 is able to suppress the formation of S. aureus biofilm, as well as to disrupt $S$. aureus preformed biofilm. Our data also show that the eradication of S. aureus preformed biofilm is associated with downregulation of the expression of several biofilmand toxin-related genes. Based on the above findings, we speculate that PYED-1 could be a promising biofilm inhibitor and biofilm destroyer, and a potential candidate drug for therapeutic regimens, with the aim of reducing the morbidity of $S$. aureus biofilm-related infections.

Author Contributions: Conceptualization, E.D.G. and A.G..; methodology, A.V., E.P.E., and A.E.; formal analysis, A.V. and E.D.G.; investigation, A.V., E.P.E.; data curation, A.G., R.Z., and E.D.G.; writing-original draft preparation, R.Z. and E.D.G.; supervision, A.G., R.Z., and E.D.G.; funding acquisition, R.Z. All authors have read and agreed to the published version of the manuscript.

Funding: This research was funded in part by a grant from the Italian Ministry of Education, University and Research (MIUR): PRIN2017 (Grant 2017SFBFER to RZ).

Acknowledgments: We gratefully acknowledge Pierpaolo Di Nocera for comments and critical reading of the manuscript.

Conflicts of Interest: The authors declare no conflict of interest. The funders had no role in the design of the study; in the collection, analyses, or interpretation of data; in the writing of the manuscript, or in the decision to publish the results.

\section{References}

1. Stoodley, P.; Sauer, K.; Davies, D.G.; Costerton, J.W. Biofilms as complex differentiated communities. Ann. Rev. Microbiol. 2002, 56, 187-209. [CrossRef]

2. Flemming, H.C.; Wingender, J. The biofilm matrix. Nat. Rev. Microbiol. 2010, 8, 623-632. [CrossRef] [PubMed]

3. Simoes, M.; Pereira, M.O.; Vieira, M.J. Effect of mechanical stress on biofilms challenged by different chemicals. Water Res. 2005, 39, 5142-5152. [CrossRef] [PubMed]

4. Parsek, M.R.; Singh, P.K. Bacterial biofilms: An emerging link to disease pathogenesis. Annu. Rev. Microbiol. 2003, 57, 677-701. [CrossRef] [PubMed]

5. Verderosa, A.D.; Totsika, M.; Fairfull-Smith, K.E. Bacterial Biofilm Eradication Agents: A Current Review. Front. Chem. 2019, 28, 824. [CrossRef] [PubMed]

6. Bjarnsholt, T. The role of bacterial biofilms in chronic infections. APMIS Suppl. 2013, 136, 1-51. [CrossRef]

7. Tong, S.Y.; Davis, J.S.; Eichenberger, E.; Holland, T.L.; Fowler, V.G.J. Staphylococcus aureus infections: Epidemiology, pathophysiology, clinical manifestations, and management. Clin. Microbiol. Rev. 2015, 28, 603-661. [CrossRef]

8. Otto, M. Staphylococcal infections: Mechanisms of biofilm maturation and detachment as critical determinants of pathogenicity. Annu. Rev. Med. 2013, 64, 175-188. [CrossRef]

9. Lister, J.L.; Horswill, A.R. Staphylococcus aureus biofilms: Recent developments in biofilm dispersal. Front. Cell Infect. Microbiol. 2014, 4, 178. [CrossRef]

10. Esposito, A.; De Gregorio, E.; De Fenza, M.; D’Alonzo, D.; Satawani, A.; Guaragna, A. Expeditious synthesis and preliminary antimicrobial activity of deflazacort and its precursors. RSC Adv. 2019, 9, 21519-21524. [CrossRef]

11. Vollaro, A.; Esposito, A.; Antonaki, E.; Iula, V.D.; D’Alonzo, D.; Guaragna, A.; De Gregorio, E. Steroid Derivatives as potential antimicrobial agents against Staphylococcus aureus planktonic cells. Microorganisms 2020, 8, 468. [CrossRef]

12. Esposito, A.; Vollaro, A.; Esposito, E.P.; D’Alonzo, D.; Guaragna, A.; Zarrilli, R.; De Gregorio, E. Antibacterial and Antivirulence Activity of Glucocorticoid PYED-1 against Stenotrophomonas maltophilia. Antibiotics (Basel) 2020, 9, 105. [CrossRef] [PubMed]

13. Costerton, J.W. Biofilms: Survival mechanisms of clinically relevant microorganisms. Clin. Microbiol. Rev. 2002, 15, 167-193. 
14. Rabin, N.; Zheng, Y.; Opoku-Temeng, C.; Du, Y.; Bonsu, E.; Sintim, H.O. Biofilm formation mechanisms and targets for developing antibiofilm agents. Future Med. Chem. 2015, 7, 493-512. [CrossRef] [PubMed]

15. Goggin, R.; Jardeleza, C.; Wormald, P.J.; Vreugde, S. Corticosteroids directly reduce Staphylococcus aureus biofilm growth: An in vitro study. Laryngoscope 2014, 124, 602-607. [CrossRef] [PubMed]

16. Brown, M.R.W.; Gilbert, P. Sensitivity of biofilms to antimicrobial agents. J. Appl. Bacteriol. 1993, 74, 87S-97S. [CrossRef] [PubMed]

17. Davies, D.; Marques, C. A fatty acid messenger is responsible for inducing dispersion in microbial biofilms. J. Bacteriol. 2009, 191, 1393-1403. [CrossRef]

18. Costerton, J.W. Bacterial biofilms: A common cause of persistent infections. Science 1999, 284, $1318-1322$. [CrossRef]

19. Rogers, S.; Huigens, R.W., III; Melander, C. A 2-aminobenzimidazole that inhibits and disperses gram-positive biofilms through a zinc-dependent mechanism. J. Am. Chem. Soc. 2009, 131, 9868-9869. [CrossRef]

20. Hall-Stoodley, L.; Stoodley, P. Evolving concepts in biofilm infections. Cell Microbiol. 2009, 11, $1034-1043$. [CrossRef]

21. Schwartz, K.; Ganesan, M.; Payne, D.E.; Solomon, M.J.; Boles, B.R. Extracellular DNA facilitates the formation of functional amyloids in Staphylococcus aureus biofilms. Mol. Microbiol. 2016, 99, 123-134. [CrossRef] [PubMed]

22. Kavanaugh, J.S.; Flack, C.E.; Lister, J.; Ricker, E.B.; Ibberson, C.B.; Jenul, C.; Moormeier, D.E.; Delmain, E.A.; Bayles, K.W.; Horswill, A.R. Identification of extracellular DNA-binding proteins in the biofilm matrix. mBio 2019, 10, e01137-19. [CrossRef] [PubMed]

23. Okshevsky, M.; Meyer, R.L. The role of extracellular DNA in the establishment, maintenance and perpetuation of bacterial biofilms. Crit. Rev. Microbiol. 2015, 41, 341-352. [CrossRef] [PubMed]

24. Rice, K.C.; Bayles, K.W. Molecular control of bacterial death and lysis. Microbiol. Mol. Biol. Rev. 2008, 72, 85-109. [CrossRef] [PubMed]

25. Ranjit, D.K.; Endres, J.L.; Bayles, K.W. Staphylococcus aureus CidA and LrgA proteins exhibit holin-like properties. J. Bacteriol. 2011, 193, 2468-2476. [CrossRef] [PubMed]

26. Sadykov, M.R.; Bayles, K.W. The control of death and lysis in staphylococcal biofilms: A coordination of physiological signals. Curr. Opin. Microbiol. 2012, 15, 211-215. [CrossRef]

27. Shen, F.; Tang, X.; Wang, Y.; Yang, Z.; Shi, X.; Wang, C.; Zhang, Q.; An, Y.; Cheng, W.; Jin, K.; et al. Phenotype and expression profile analysis of Staphylococcus aureus biofilms and planktonic cells in response to licochalcone A. Appl. Microbiol. Biotechnol. 2015, 99, 359-373. [CrossRef]

28. Zhao, X.; Liu, Z.; Liu, Z.; Meng, R.; Shi, C.; Chen, X.; Bu, X.; Guo, N. Phenotype and RNA-seq-Based transcriptome profiling of Staphylococcus aureus biofilms in response to tea tree oil. Microb. Pathog. 2018, 123, 304-313. [CrossRef]

29. Wang, D.; Jin, Q.; Xiang, H.; Wang, W.; Guo, N.; Zhang, K.; Tang, X.; Meng, R.; Feng, H.; Liu, L.; et al. Transcriptional and functional analysis of the effects of magnolol: Inhibition of autolysis and biofilms in Staphylococcus aureus. PLoS ONE 2011, 6, e26833. [CrossRef]

30. Fernandez, L.; Gonzalez, S.; Campelo, A.B.; Martinez, B.; Rodriguez, A.; Garcia, P. Downregulation of autolysin-encoding genes by phage-derived lytic proteins inhibits biofilm formation in Staphylococcus aureus. Antimicrob. Agents Chemother. 2017, 61, e02724-16. [CrossRef]

31. Wang, J.; Nong, X.H.; Zhang, X.Y.; Xu, X.Y.; Amin, M.; Qi, S.H. Screening of anti-biofilm compounds from marine-derived fungi and the effects of secalonic acid D on Staphylococcus aureus biofilm. J. Microbiol. Biotechnol. 2017, 27, 1078-1089. [CrossRef] [PubMed]

32. Paharik, A.E.; Horswill, A.R. The staphylococcal biofilm: Adhesins, regulation, and host response. Microbiol. Spectr. 2016, 4. [CrossRef] [PubMed]

33. Mainiero, M.; Goerke, C.; Geiger, T.; Gonser, C.; Herbert, S.; Wolz, C. Differential target gene activation by the Staphylococcus aureus two-component system saeRS. J. Bacteriol. 2010, 192, 613-623. [CrossRef] [PubMed]

34. Voyich, J.M.; Vuong, C.; DeWald, M.; Nygaard, T.K.; Kocianova, S.; Griffith, S.; Jones, J.; Iverson, C.; Sturdevant, D.E.; Braughton, K.R.; et al. The SaeR/S gene regulatory system is essential for innate immune evasion by Staphylococcus aureus. J. Infect. Dis. 2009, 199, 1698-1706. [CrossRef]

35. Geiger, T.; Goerke, C.; Mainiero, M.; Kraus, D.; Wolz, C. The virulence regulator Sae of Staphylococcus aureus: Promoter activities and response to phagocytosis-related signals. J. Bacteriol. 2008, 190, 3419-3428. [CrossRef] [PubMed] 
36. Tsang, L.H.; Cassat, J.E.; Shaw, L.N.; Beenken, K.E.; Smeltzer, M.S. Factors contributing to the biofilm-deficient phenotype of Staphylococcus aureus sarA mutants. PLoS ONE 2008, 3, e3361. [CrossRef] [PubMed]

37. Zielinska, A.K.; Beenken, K.E.; Joo, H.S.; Mrak, L.N.; Griffin, L.M.; Luong, T.T.; Lee, C.Y.; Otto, M.; Shaw, L.N.; Smeltze, M.S. Defining the strain-dependent impact of the staphylococcal accessory regulator (sarA) on the alpha-toxin phenotype of Staphylococcus aureus. J. Bacteriol. 2011, 193, 2948-2958. [CrossRef]

38. Huseby, M.J.; Kruse, A.C.; Digre, J.; Kohler, P.L.; Vocke, J.A.; Mann, E.E.; Bayles, K.W.; Bohach, G.A.; Schlievert, P.M.; Ohlendorf, D.H.; et al. Beta toxin catalyzes formation of nucleoprotein matrix in staphylococcal biofilms. Proc. Natl. Acad. Sci. USA 2010, 107, 14407-14412. [CrossRef]

39. Mrak, L.N.; Zielinska, A.K.; Beenken, K.E.; Mrak, I.N.; Atwood, D.N.; Griffin, L.M.; Lee, C.Y.; Smeltzer, M.S. saeRS and sarA act synergistically to repress protease production and promote biofilm formation in Staphylococcus aureus. PLoS ONE 2012, 7, e38453. [CrossRef]

40. Arya, R.; Ravikumar, R.; Santhosh, R.S.; Princy, S.A. SarA based novel therapeutic candidate against Staphylococcus aureus associated with vascular graft infections. Front. Microbiol. 2015, 6, 416. [CrossRef]

41. Balamurugan, P.; Praveen Krishna, V.; Bharath, D.; Lavanya, R.; Vairaprakash, P.; Adline Princy, S. Staphylococcus aureus quorum regulator SarA targeted compound, 2-[(Methylamino) methyl] phenol inhibits biofilm and down-regulates virulence genes. Front. Microbiol. 2017, 8, 1290-1300. [CrossRef] [PubMed]

42. Cheung, G.Y.; Wang, R.; Khan, B.A.; Sturdevant, D.E.; Otto, M. Role of the accessory gene regulator agr in community-associated methicillin-resistant Staphylococcus aureus pathogenesis. Infect. Immun. 2011, 79, 1927-1935. [CrossRef] [PubMed]

43. Bischoff, M.; Entenza, J.M.; Giachino, P. Influence of a functional sigB operon on the global regulators sar and agr in Staphylococcus aureus. J. Bacteriol. 2011, 83, 5171-5179. [CrossRef]

44. Lauderdale, K.J.; Boles, B.R.; Cheung, A.L.; Horswill, A.R. Interconnections between Sigma B, agr, and proteolytic activity in Staphylococcus aureus biofilm maturation. Infect. Immun. 2009, 77, 1623-1635. [CrossRef] [PubMed]

45. O'Riordan, K.; Lee, J.C. Staphylococcus aureus capsular polysaccharides. Clin. Microbiol. Rev. 2004, 17, $218-234$. [CrossRef] [PubMed]

46. Pane, K.; Cafaro, V.; Avitabile, A.; Torres, M.T.; Vollaro, A.; De Gregorio, E.; Catania, M.R.; Di Maro, A.; Bosso, A.; Gallo, G.; et al. Identification of novel cryptic multifunctional antimicrobial peptides from the human stomach enabled by a computational-experimental platform. ACS Synth. Biol. 2018, 7, 2105-2115. [CrossRef]

47. De Gregorio, E.; Esposito, E.P.; Zarrilli, R.; Di Nocera, P.P. Contact-dependent growth inhibition proteins in Acinetobacter baylyi ADP1. Curr. Microbiol. 2018, 75, 1434-1440. [CrossRef]

48. Martinucci, M.; Roscetto, E.; Iula, V.D.; Votsi, A.; Catania, M.R.; De Gregorio, E. Accurate identification of members of the Burkholderia cepacia complex in cystic fibrosis sputum. Lett. Appl. Microbiol. 2016, 62, 221-229. [CrossRef]

49. Livak, K.J.; Schmittgen, T.D. Analysis of relative gene expression data using real-time quantitative PCR and the 2(-Delta Delta C(T)) Method. Methods 2001, 25, 402-408. [CrossRef]

(C) 2020 by the authors. Licensee MDPI, Basel, Switzerland. This article is an open access article distributed under the terms and conditions of the Creative Commons Attribution (CC BY) license (http://creativecommons.org/licenses/by/4.0/). 